\title{
Coregulation Supervision Strategy of Drug Enterprises under the Government Reward and Punishment Mechanism
}

\author{
Siyi Zhang' and Lilong Zhu $\mathbb{D}^{1,2}$ \\ ${ }^{1}$ School of Business, Shandong Normal University, Jinan 250014, China \\ ${ }^{2}$ Quality Research Center, Shandong Normal University, Jinan 250014, China \\ Correspondence should be addressed to Lilong Zhu; zhulilong2008@126.com
}

Received 10 August 2021; Revised 23 September 2021; Accepted 24 September 2021; Published 18 October 2021

Academic Editor: Abdellatif Ben Makhlouf

Copyright (c) 2021 Siyi Zhang and Lilong Zhu. This is an open access article distributed under the Creative Commons Attribution License, which permits unrestricted use, distribution, and reproduction in any medium, provided the original work is properly cited.

\begin{abstract}
Considering the government reward and punishment mechanism and the collusion behavior between third-party testing agencies and drug enterprises, based on the coregulation information platform, this paper constructs an evolutionary game model of coregulation supervision, which involves the participation of local government, drug enterprises, and third-party testing agencies. The stable equilibrium points of each participant's strategic choices are solved. The stability of the strategic combination is analyzed by Lyapunov's first method, and MATLAB 2020b is used for simulation analysis to verify the influence of each decision variable on different players' strategic choices. The results show that, firstly, the government-increased awards and penalties will promote the integrity of drug enterprises and noncollusion of third-party testing agencies, but it is not conducive to strict performance of regulatory responsibilities by the local government. Secondly, the provision of real drug test reports by third-party testing agencies to the coregulation information platform can supervise drug enterprises and restrict local government to perform its duty. Thirdly, the central government's punishment to the local government's dereliction of duty is significant to enhancing the robustness of drug enterprises' integrity operation. Furthermore, reasonably setting rewards and punishments and perfecting the coregulation information platform will help form a coregulation pattern of government supervision, self-discipline of drug enterprises, and social supervision. Finally, drug quality is highly related to whether drug enterprises operate with integrity. Standardizing coregulation supervision of drug enterprises' integrity operation is the key to ensuring the safety of the source of drug quality. Therefore, this paper enriches and expands the theoretical basis of the coregulation supervision of drug enterprises' integrity operation and proposes corresponding countermeasures and suggestions.
\end{abstract}

\section{Introduction}

In recent years, drug enterprises' integrity operation affects drug quality and safety, which is related to people's life and health, economic development, and social stability. The World Health Organization (WHO) recommends that government be responsible for establishing national medicine regulatory agencies (MRA), clarify their responsibilities, exert effective market control capabilities, and establish a monitoring and evaluation mechanism. The US Food and Drug Administration (FDA) focuses on cultivating talents and setting up regulatory scientific institutions to effectively fill the knowledge gaps in the research and development of drugs, reduce the uncertainty of regulatory decision-making, and ensure that drug enterprises produce high-quality drugs to meet the needs of patients and the market. The European Medicines Agency (EMA) has established a relatively complete drug risk supervision system for a long time to ensure that the public can use drugs safely and effectively. The Pharmaceuticals and Medical Devices Agency (PMDA) of Japan has gradually attached importance to the development of regulatory science, giving full play to its functions in drug testing, new drug applications, inspection and conformity assessment of drug enterprises management practices, and so on.

Over the years, India has learned from the experience of Western countries in drug supervision and has continuously adjusted its management structure. It has established a central 
drug management agency and a central drug standard control organization to be fully responsible for drug standards and inspections and provide drug enterprises with reference standards for various drugs. After years of practice, Australia has gradually established a relatively complete drug regulatory system. Through the joint consultation of industry members, the opinions and suggestions of member enterprises are reflected on the government in order to exert influence on government decision-making. The drug administration shall perform supervision and management functions within the scope prescribed by law and implement appropriate reward and punishment mechanisms. The Chinese government also has very strict regulatory requirements for drug enterprises. In order to promote scientific drug supervision and continue to build a healthy China, it has carried out international exchanges and technology introduction and established a scientific and reasonable drug enterprises supervision system based on national conditions (the above information comes from the official website of the World Health Organization, the European Union, and national medicine regulatory agencies of countries, such as FDA, EMA, PMDA, CIPL, TGA, and NMPA).

Therefore, this paper considers the government reward and punishment mechanism [1], based on the coregulation information platform, and constructs an evolutionary game model [2] involving the participation of local government, drug enterprises, and third-party testing agencies. Evolutionary game theory [3] is an effective method to study the dynamic changes of the strategy of the subject of bounded rationality in the process of long-term repeated games under the condition of asymmetric information [4]. Its strategic choice is continuously adjusted over time [5]. By the stability theorem of replication dynamic system and Lyapunov's first method, the stability of the strategic combination and the influence of changes in decision variables on strategic choice are analyzed [6], which are aiming to solve the following three problems: at first, how does the reward and punishment mechanism affect the strategic choices of three participants, then how to play the role in the coregulation information platform to promote the coregulation supervision, and finally, how does the participation of local government and third-party testing agencies affect the strategic choices of drug enterprises.

The remaining parts of this paper are arranged as follows: Section 2 combs and reviews the relevant literature; Section 3 makes hypotheses and constructs an evolutionary game model which involves local government, drug enterprises, and third-party testing agencies; Section 4 analyzes the stability of the strategic choice of the three participants; Section 5 analyzes the stability of strategic combination according to Lyapunov's first method; Section 6 is the simulation analysis with MATLAB 2020b; Section 7 discusses and outlines related suggestions; and Section 8 provides the conclusions.

\section{Relevant Literature}

Nonintegrity operation of drug enterprises refers to the fact that the procurement, production, inspection, storage, and sales of drugs do not meet GSP management standards, resulting in low-quality drugs. After drugs are marketed, strong data-driven methods are needed to support and enhance regulatory decision-making [7]; once a drug quality accident occurs, the scope of risk exposure is difficult to control [8]. The outbreak of COVID-19 in 2019 has aroused widespread attention from various drug enterprises on the development of new effective drugs [9] and has strengthened the key performance of the rapid development and survival of drug enterprises [10]. Therefore, the issue of drug quality and safety has attracted widespread attention from all walks of life. In recent years, many scholars have done a lot of research work in drug enterprises operation, government supervision, and third-party participation, which have provided a preliminary basis for the research of this paper.

The motivation for nonintegrity operation and lower production standards of drug enterprises is to seek greater benefits [11]; the participation of third-party testing agencies in collusion makes it more difficult to contain, which seriously affects drug quality and safety. The problems and potential hidden dangers in the field of drug quality and safety cannot be underestimated [12]. Regulatory channels are becoming more and more extensive [13], but the cost of surprise inspections is high, which is not conducive to the self-discipline of enterprises [14]. Compared with other national drug safety monitoring systems, China currently lacks postmarketing supervision of drugs [15], and drug enterprises have failed to fulfill their social responsibilities [16]. The establishment of a digital information platform is the future trend of drug enterprises supervision [17], and the government should play a more active role in further optimizing the decision-making process [18]. Economic incentives can promote the integrity behavior of drug enterprises [19], and the government reward and punishment mechanism can effectively promote the active operation of enterprises [20], give full play to market vitality, and maintain good market order.

The recorded feedback of test results from participants outside the government can play a key role in strengthening and maintaining a country's regulatory system [21]. Thirdparty participation has a positive role in promoting efficient government supervision [22] and is conducive to standardizing the behavior of drug enterprises, achieving regulatory goals [23], and advancing the quality supervision mechanism technically and objectively. However, there will be a risk of collusion, and collusive behavior will produce negative effects [24]. Establishing a collusion fine mechanism can play a deterrent effect [25], and strengthening information disclosure and perfecting reputation mechanisms can curb collusive behavior [26] and improve the efficiency of supervision.

In summary, the existing literature mainly discusses the role of local government, drug enterprises, and third-party testing agencies in drug quality supervision from the perspective of a single player. There is still a lack of consideration of three participants from the perspective of coregulation supervision. In addition, the influence of thirdparty testing agencies' collusion behavior and government reward and punishment mechanism on the different strategic choices of each participant in the coregulation supervision is not taken into account. 
Therefore, the research contributions of this paper have the following three points. Firstly, considering the government reward and punishment mechanism, based on the coregulation information platform, this paper builds a game model of tripartite participation involving local government, drug enterprises, and third-party testing agencies; secondly, considering the influence of the collusion and noncollusion of third-party testing agencies on the strategic choices of other participants, the evolutionary stable strategic combination under different conditions is solved; finally, the influence of each decision variable on the strategic choices of the three participants is solved and analyzed. And through MATLAB 2020b simulation analysis, the validity of the model is verified, and countermeasures and suggestions are put forward for coregulation supervision.

\section{Model Hypotheses and Construction}

This paper chooses the evolutionary game as the research method because it abandons the assumption of complete rationality. A research object is a certain group that changes over time. It can explain the dynamic process of the evolution of each stakeholder's strategic choice and explain why this state has been reached and how to reach it. Economists often use evolutionary game theory to analyze the influencing factors and the formation process of social habits, norms, or institutions. Of course, when building a game model, the assumptions made for various relationships often deviate slightly from reality and need to be considered repeatedly, not only to meet the actual situation but also to ensure the feasibility of the model. Therefore, after repeated discussion, the evolutionary game structure relationship involving local government, drug enterprises, and thirdparty testing agencies is shown in Figure 1.

Figure 1 is the structural relationship diagram that shows the relationship among the local government, drug enterprises, and third-party testing agencies based on the coregulation information platform under the government reward and punishment mechanism.

3.1. Model Hypotheses. This paper considers the benefits of different strategies of the local government, drug enterprises, and third-party testing agencies under coregulation supervision. In order to solve the evolutionary stable strategic combination in different situations and analyze the influence of each decision variable on the strategic choices of the three participants, the following hypotheses are made:

H1: the local government is participant 1 , the drug enterprise is participant 2, and the third-party testing agency is participant 3 . The three players are bounded rational participants. The strategic choice space of the local government is $\alpha=\left(\alpha_{1}, \alpha_{2}\right)=$ (strictly supervise, loosely supervise), chooses $\alpha_{1}$ with the probability of $x$, and chooses $\alpha_{2}$ with the probability of $1-x, x \in[0,1]$. The strategic choice space of drug enterprises is $\beta=$ $\left(\beta_{1}, \beta_{2}\right)=$ (integrity operate, nonintegrity operate), chooses $\beta_{1}$ with the probability of $y$, and chooses $\beta_{2}$ with the probability of $1-y, y \in[0,1]$. The strategic choice space of the third-party testing agencies is $\gamma=$ $\left(\gamma_{1}, \gamma_{2}\right)=$ (noncollusion, collusion), chooses $\gamma_{1}$ with the probability of $z$, and chooses $\gamma_{2}$ with the probability of $1-z, z \in[0,1]$.

$\mathrm{H} 2$ : the income from the operation of drug enterprises is $R$, the cost of integrity operation of drug enterprises is $C_{h}$, and the cost of nonintegrity operation of drug enterprises is $C_{l}\left(C_{h}>C_{l}\right)$. When drug enterprises do not operate with integrity, they will seek collusion with the third-party testing agencies to pass the test; the cost of seeking collusion is $B$.

H3: the cost of strict supervision by the local government is $G_{h}$, and the cost of loose supervision is $G_{l}$, $\left(G_{h}>G_{l}\right)$. When the local government strictly supervises, the drug enterprises that operate without integrity will be fined, and the fine is $F_{e}$. The third-party testing agencies that participate in collusion will also be fined, and the fine is $F_{p}$. Third-party testing agencies that do not participate in collusion will be rewarded, and the reward is $M$.

H4: the integrity operation of drug enterprises is conducive to the life and health of the public and the stable development of the social economy, which brings social benefits to the local government; let the social benefits be $H$. When drug enterprises operate with nonintegrity but third-party testing agencies do not participate in the collusion, the local government with loose supervision will be punished by the central government (such as administrative removal and administrative accountability); let the penalty be $F_{\mathrm{g}}$.

H5: the income of the third-party testing agencies is $V$, and their detection cost is $C_{p}$. When drug enterprises operate without integrity, if the third-party testing agencies do not participate in collusion, they will issue real test reports; if third-party testing agencies choose collusion, they need to forge test records and issue false test reports. Let the speculative cost of collusion be $C_{t}\left(C_{t}<B\right)$.

The parameters and descriptions of this paper are shown in Table 1.

3.2. Model Construction. Based on the above hypotheses, this paper constructs a three-party mixed strategy game matrix for local government, drug enterprises, and thirdparty testing agencies, as shown in Table 2 .

\section{Analysis of the Strategic Choice Stability}

4.1. The Local Government's Strategic Choice Stability. The expected benefit of local government choosing the "strict supervision" strategy is 


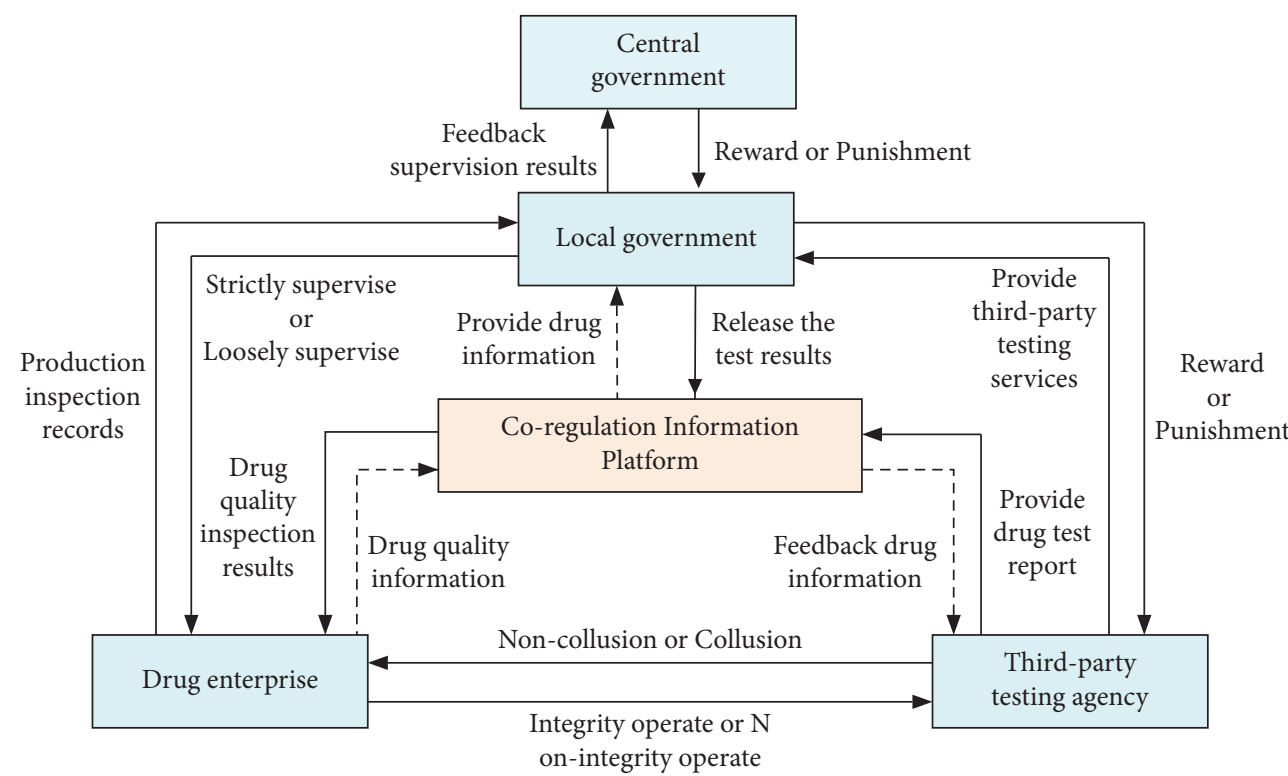

FIGURE 1: Three-party evolutionary game structure relationship.

TABLE 1: Related parameter description.

\begin{tabular}{lccc}
\hline Parameter & Description & Parameter & Description \\
\hline$x$ & Probability of local government choosing strict & $F_{e}$ & Fines for nonintegrity operation of drug enterprises \\
$y$ & supervision & $F_{p}$ & Fines for collusion of third-party testing agencies \\
$z$ & Probability of integrity operation of drug enterprises & $M$ & Incentives obtained from third-party testing agencies \\
$R$ & Income of drug enterprises & $H$ & Social benefits of local government \\
$C_{h}$ & The cost of integrity operation of drug enterprises & $F_{g}$ & Punishment for loose supervision of local government \\
$C_{l}$ & The cost of nonintegrity operation of drug enterprises & $C_{p}$ & Detection cost of third-party testing agencies \\
$B$ & The cost of drug enterprises seeking collusion & $V$ & Testing income of third-party testing agencies \\
$G_{h}$ & The cost of strict supervision of local government & $C_{t}$ & Speculation cost of third-party testing agencies \\
$G_{l}$ & The cost of loose supervision of local government & & \\
\hline
\end{tabular}

TABle 2: Three-party mixed strategy game matrix.

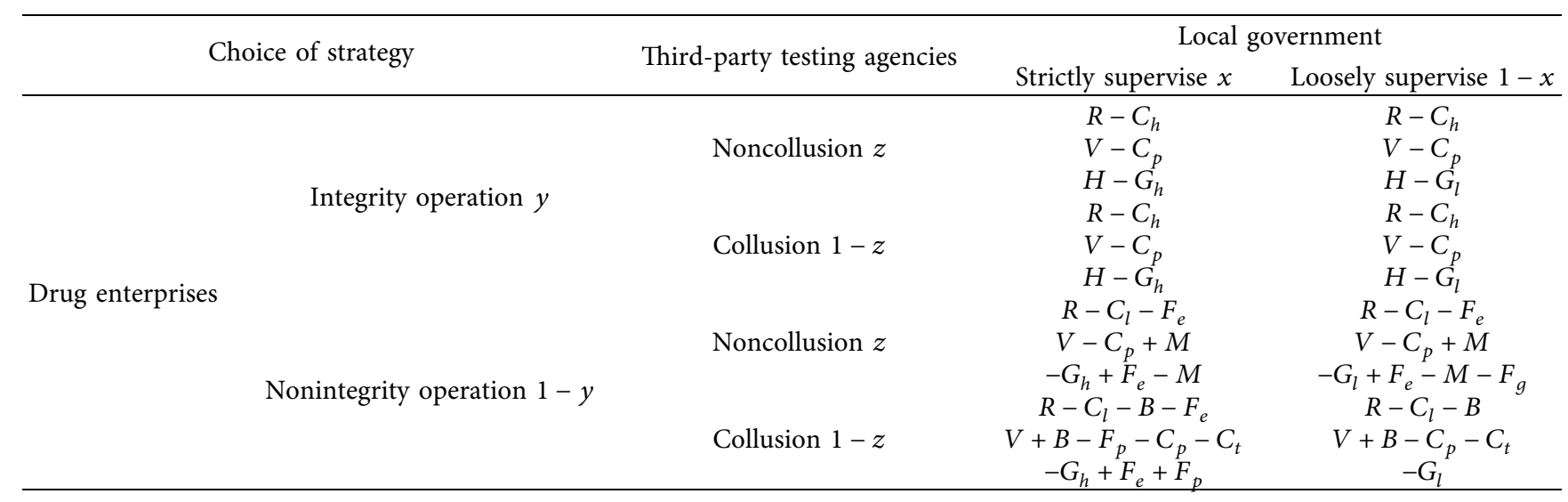

$$
\begin{aligned}
E_{x} & =y z\left(H-G_{h}\right)+y(1-z)\left(H-G_{h}\right)+(1-y) z\left(-G_{h}+F_{e}-M\right)+(1-y)(1-z)\left(-G_{h}+F_{e}+F_{p}\right) \\
& =y\left(H-F_{e}-F_{p}\right)-(1-y) z\left(F_{p}+M\right)-G_{h}+F_{e}+F_{p} .
\end{aligned}
$$


The expected benefit of local government choosing the "loose supervision" strategy is

$$
\begin{aligned}
E_{1-x} & =y z\left(H-G_{l}\right)+y(1-z)\left(H-G_{l}\right)+(1-y) z\left(-G_{l}+F_{e}-M-F_{g}\right)+(1-y)(1-z)\left(-G_{l}\right) \\
& =y H+(1-y) z\left(F_{e}-M-F_{g}\right)-G_{l} .
\end{aligned}
$$

The replicated dynamic equation and the first derivative of the local government's strategic choice are

$$
\begin{aligned}
F(x) & =\frac{\mathrm{d} x}{\mathrm{~d} t}=x\left(E_{x}-\bar{E}\right)=x(1-x)\left(E_{x}-E_{1-x}\right) \\
& =x(1-x)\left[(1-y) z\left(F_{g}-F_{p}-F_{e}\right)-y\left(F_{p}+F_{e}\right)+G_{l}-G_{h}+F_{e}+F_{p}\right], \\
F^{\prime}(x) & =(1-2 x)\left[(1-y) z\left(F_{g}-F_{p}-F_{e}\right)-y\left(F_{p}+F_{e}\right)+G_{l}-G_{h}+F_{e}+F_{p}\right] .
\end{aligned}
$$

According to the stability theorem of differential equations, if the probability of the local government choosing the "strict supervision" strategy is to be in a stable state, the following conditions must be met: $F(x)=0$ and $F^{\prime}(x)<0$.

Proposition 1. When $y<y_{0}$, the local government's stabilization strategy is "strict supervision." When $y>y_{0}$, its stabilization strategy is "loose supervision." When $y=y_{0}$, we are unable to determine its stabilization strategy. The threshold is $y_{0}=1-\left(\left(G_{h}-G_{l}\right) /\left(z\left(F_{g}-F_{p}-F_{e}\right)+F_{p}+F_{e}\right)\right)$.

Proof. Make $G(y)=(1-y) z\left(F_{g}-F_{p}-F_{e}\right)-y\left(F_{p}+F_{e}\right)+$ $G_{l}-G_{h}+F_{e}+F_{p}$, when $G(y)=0, \quad y_{0}=1-\left(\left(G_{h}-G_{l}\right) /\right.$ $\left.\left(z\left(F_{g}-F_{p}-F_{e}\right)+F_{p}+F_{e}\right)\right)$ can be calculated. Because $\partial G(y) / \partial y<0, G(y)$ is a decreasing function of $y$. When $y<y_{0}, G(y)>0,\left.F^{\prime}(x)\right|_{x=1}<0$, and $\left.F(x)\right|_{x=1}=0$ can be calculated, so $x=1$ is stable. When $y>y_{0}, G(y)<0$, $\left.F^{\prime}(x)\right|_{x=0}<0$, and $\left.F(x)\right|_{x=0}=0$ can be calculated, so $x=0$ is stable. When $y=y_{0}, G(y)=0$, and $F^{\prime}(x)=0$ can be calculated, we are unable to determine a stable strategy.

Proposition 1 shows that if $y$ decreases, the local government's stabilization strategy will change from loose supervision to strict supervision. Therefore, when the local government realizes that the probability of drug enterprises' nonintegrity operation is high, in order to ensure the public health and the stability of market order, it will strictly supervise the drug enterprises.

In summary, the response function of $x$ is

$$
x= \begin{cases}0, & \text { if } y>1-\frac{G_{h}-G_{l}}{z\left(F_{g}-F_{p}-F_{e}\right)+F_{p}+F_{e}}, \\ {[0,1],} & \text { if } y=1-\frac{G_{h}-G_{l}}{z\left(F_{g}-F_{p}-F_{e}\right)+F_{p}+F_{e}}, \\ 1, & \text { if } y<1-\frac{G_{h}-G_{l}}{z\left(F_{g}-F_{p}-F_{e}\right)+F_{p}+F_{e}} .\end{cases}
$$

According to Proposition 1, the phase diagram of local government strategic choice is shown in Figure 2.

Figure 2 shows the phase diagram that shows the evolutionary trend of the local government's strategy obtained by calculating the response function of the probability of the local government choosing the "strict supervision" strategy.

It can be seen from Figure 2 that the volume of $V_{g 1}$ is the probability that the local government chooses the "strict 


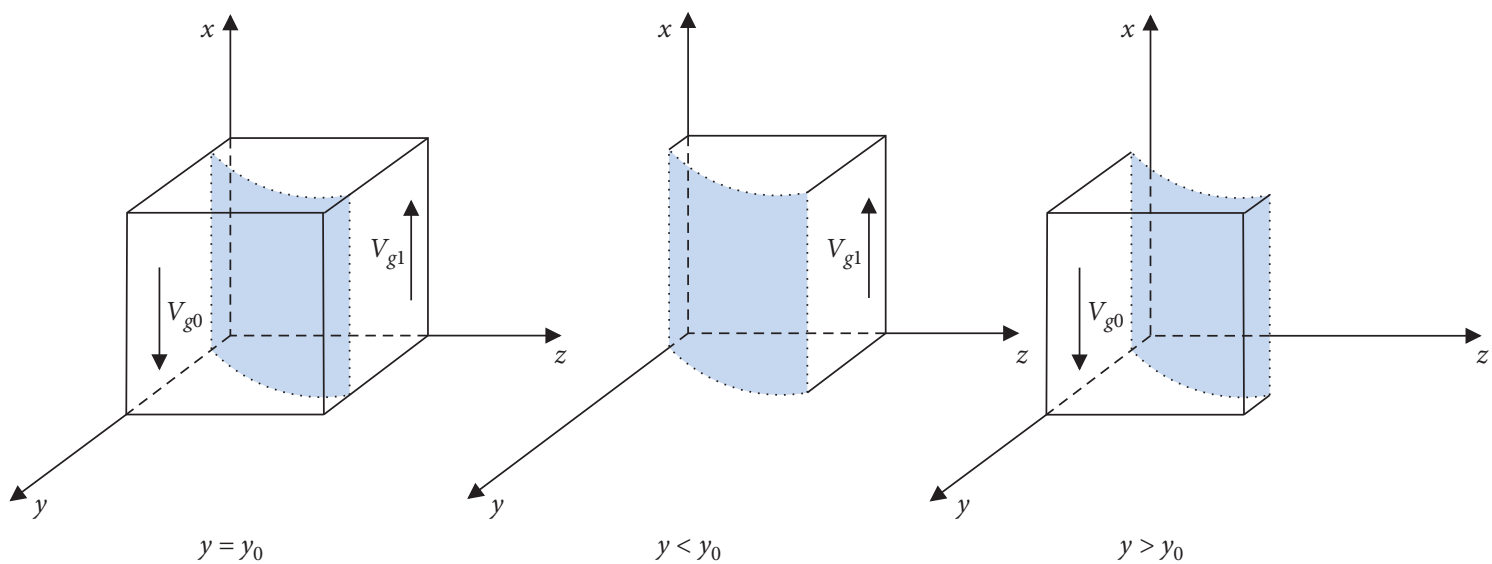

Figure 2: Phase diagram of the local government strategic choice.

supervision" strategy, and the volume of $V_{g 0}$ is the probability that the local government chooses the "loose supervision" strategy. And,

$$
\begin{aligned}
& V_{g 1}=\int_{0}^{1} \int_{0}^{1} 1-\frac{G_{h}-G_{l}}{z\left(F_{g}-F_{p}-F_{e}\right)+F_{p}+F_{e}} \mathrm{~d} z \mathrm{~d} x=1-\frac{G_{h}-G_{l}}{F_{g}-F_{p}-F_{e}} \ln \frac{F_{g}}{F_{p}+F_{e}}, \\
& V_{g 0}=1-V_{g 1}=\frac{G_{h}-G_{l}}{F_{g}-F_{p}-F_{e}} \ln \frac{F_{g}}{F_{p}+F_{e}} .
\end{aligned}
$$

Corollary 1. When the local government pays less additional costs for strict supervision and imposes more fines on drug enterprises, it tends more to choose the "strict supervision" strategy.
Proof. According to the probability $V_{g 1}$, the first-order partial derivatives of $\left(G_{h}-G_{l}\right)$ and $F_{e}$ can be calculated:

$$
\begin{aligned}
\frac{\partial V_{g 1}}{\partial\left(G_{h}-G_{l}\right)} & =-\frac{G_{h}-G_{l}}{F_{g}-F_{p}-F_{e}} \ln \frac{F_{g}}{F_{p}+F_{e}}<0, \\
\frac{\partial V_{g 1}}{\partial F_{e}} & =\frac{G_{h}-G_{l}}{\left(F_{g}-F_{p}-F_{e}\right)\left(F_{p}+F_{e}\right)}-\frac{G_{h}-G_{l}}{\left(F_{g}-F_{p}-F_{e}\right)^{2}} \ln \frac{F_{g}}{F_{p}+F_{e}}>0 .
\end{aligned}
$$

Corollary 1 shows that reducing the cost of strict supervision can increase the probability of choosing a "strict supervision" strategy; increasing the fines for nonintegrity drug enterprises can increase the possibility of strict supervision by the local government.

Corollary 2. The higher the penalties for loose supervision by local government and the more fines imposed on third-party testing agencies, the lower the probability that local government will choose the "loose supervision" strategy.

Proof. According to the probability $V_{g 0}$, the first-order partial derivatives of $F_{g}$ and $F_{p}$ can be calculated:

$$
\begin{aligned}
& \frac{\partial V_{g 0}}{\partial F_{g}}=-\left[\frac{G_{h}-G_{l}}{\left(F_{g}-F_{p}-F_{e}\right)^{2}} \ln \frac{F_{g}}{F_{p}+F_{e}}-\frac{G_{h}-G_{l}}{\left(F_{g}-F_{p}-F_{e}\right) F_{g}}\right]<0, \\
& \frac{\partial V_{g 0}}{\partial F_{p}}=-\left[\frac{G_{h}-G_{l}}{\left(F_{g}-F_{p}-F_{e}\right)\left(F_{p}+F_{e}\right)}-\frac{G_{h}-G_{l}}{\left(F_{g}-F_{p}-F_{e}\right)^{2}} \ln \frac{F_{g}}{F_{p}+F_{e}}\right]<0 .
\end{aligned}
$$

Corollary 2 shows that the greater the punishment or accountability of local government loose supervision by the central government is, the more it can restrain the behavior of local government, and the probability of local government choosing "loose supervision" strategy will be reduced. As the fines colluded by third-party testing agencies are higher, the local government is unwilling to choose the "loose supervision" strategy. 
Corollary 3. When $F_{g}>F_{g 0}$, the local government will choose the "strict supervision" strategy. When $F_{g}<F_{g 0}$, it will choose the "loose supervision" strategy. The threshold is $F_{g 0}=$ $\left(\left(y\left(F_{p}+F_{e}\right)+G_{h}-G_{l}-F_{e}-F_{p}\right) /(z(1-y))\right)+F_{p}+F_{e}$.

Proof. According to Proposition 1, when $G(y)=0, F_{g 0}=$ $\left(\left(y\left(F_{p}+F_{e}\right)+G_{h}-G_{l}-F_{e}-F_{p}\right) /(z(1-y))\right)+F_{p}+F_{e}$ can be calculated. Because $\partial G(y) / \partial F_{g}>0, G(y)$ is an increasing function of $F_{g}$. When $F_{g}>F_{g 0}, G(y)>0$, $\left.F^{\prime}(x)\right|_{x=1}<0$, and $\left.F(x)\right|_{x=1}=0$ can be calculated. When $F_{g}<F_{g 0}, G(y)<0,\left.F^{\prime}(x)\right|_{x=0}<0$, and $\left.F(x)\right|_{x=0}=0$ can be calculated.
Corollary 3 shows that when local government loosely supervises, it will be punished by the central government. If $F_{g}>F_{g 0}$, it is possible to ensure that the local government chooses the "strict supervision" strategy. Therefore, the central government should increase accountability and penalties to urge the local government to actively fulfill its regulatory obligations and maintain good market order.

4.2. Drug Enterprises'Strategic Choice Stability. The expected benefit of drug enterprises choosing the "integrity operation" strategy is

$$
E_{y}=z x\left(R-C_{h}\right)+z(1-x)\left(R-C_{h}\right)+(1-z) x\left(R-C_{h}\right)+(1-z)(1-x)\left(R-C_{h}\right)=R-C_{h} .
$$

The expected benefit of drug enterprises choosing the "nonintegrity operation" strategy is

$$
\begin{aligned}
E_{1-y} & =z\left(R-C_{l}-F_{e}\right)+(1-z) x\left(R-C_{l}-B-F_{e}\right)+(1-z)(1-x)\left(R-C_{l}-B\right) \\
& =z\left(B-F_{e}\right)-(1-z) x F_{e}+R-C_{l}-B .
\end{aligned}
$$

The replicated dynamic equation and the first derivative of the drug enterprises' strategic choice are

$$
\begin{aligned}
F(y) & =\frac{\mathrm{d} y}{\mathrm{~d} t}=y\left(E_{y}-\bar{E}\right)=y(1-y)\left(E_{y}-E_{1-y}\right) \\
& =y(1-y)\left[C_{l}-C_{h}+B-z\left(B-F_{e}\right)+(1-z) x F_{e}\right], \\
F^{\prime}(y) & =(1-2 y)\left[C_{l}-C_{h}+B-z\left(B-F_{e}\right)+(1-z) x F_{e}\right] .
\end{aligned}
$$

According to the stability theorem of differential equations, if the probability of drug enterprises choosing the "integrity operation" strategy is to be in a stable state, the following conditions must be met: $F(y)=0$ and $F^{\prime}(y)<0$.

Proposition 2. When $x>x_{1}$, the drug enterprises' stabilization strategy is "integrity operation." When $x<x_{1}$, their stabilization strategy is "nonintegrity operation." When $x=x_{1}$, unable to determine their stabilization strategy. The threshold is $x_{1}=\left(C_{h}-C_{l}+z\left(B-F_{e}\right)-B\right) /\left((1-z) F_{e}\right)$.

Proof. Make $H(x)=C_{l}-C_{h}+B-z\left(B-F_{e}\right)+(1-z) x F_{e}$; when $H(x)=0, x_{1}=\left(C_{h}-C_{l}+z\left(B-F_{e}\right)-B\right) /\left((1-z) F_{e}\right)$ can be calculated. Because $\partial H(x) / \partial x>0, H(x)$ is an increasing function of $x$. When $x>x_{1}, H(x)>0,\left.F^{\prime}(y)\right|_{y=1}<0$, and $\left.F(y)\right|_{y=1}=0$ can be calculated, so $y=1$ is stable. When $x<x_{1}, H(x)<0,\left.F^{\prime}(y)\right|_{y=0}<0$, and $\left.F(y)\right|_{y=0}=0$ can be calculated, so $y=0$ is stable. When $x=x_{1}, H(x)=0$, and
$F^{\prime}(y)=0$ can be calculated, we are unable to determine a stable strategy.

Proposition 2 shows, when $x$ increases, the stability strategy of drug enterprises changes from nonintegrity operation to integrity operation. Therefore, when the local government strictly supervises, the drug enterprises will take the initiative to conduct integrity operation to avoid being punished.

In summary, the response function of $y$ is

$$
y= \begin{cases}0 & \text { if } x<\frac{C_{h}-C_{l}+z\left(B-F_{e}\right)-B}{(1-z) F_{e}}, \\ {[0,1]} & \text { if } x=\frac{C_{h}-C_{l}+z\left(B-F_{e}\right)-B}{(1-z) F_{e}}, \\ 1 & \text { if } x>\frac{C_{h}-C_{l}+z\left(B-F_{e}\right)-B}{(1-z) F_{e}},\end{cases}
$$


According to Proposition 2, the phase diagram of drug enterprises' strategic choice is shown in Figure 3.

Figure 3 is the phase diagram that shows the evolutionary trend of drug enterprises' strategy obtained by calculating the response function of the probability of the drug enterprises choosing the "integrity operation" strategy.
It can be seen from Figure 3 that the volume of $V_{e 1}$ is the probability that the drug enterprises choose the "integrity operation" strategy, and the volume of $V_{e 0}$ is the probability that the drug enterprises choose the "nonintegrity operation" strategy. And,

$$
\begin{aligned}
& V_{e 0}=\int_{0}^{1} \int_{0}^{\left(B-C_{h}+C_{l}\right) /\left(B-F_{e}\right)} \frac{C_{h}-C_{l}+z\left(B-F_{e}\right)-B}{(1-z) F_{e}} \mathrm{~d} z \mathrm{~d} y=\frac{C_{h}-C_{l}-B}{F_{e}}-\frac{C_{h}-C_{l}-F_{e}}{F_{e}} \ln \left(\frac{C_{h}-C_{l}-F_{e}}{B-F_{e}}\right), \\
& V_{e 1}=1-V_{e 0}=1-\frac{C_{h}-C_{l}-B}{F_{e}}+\frac{C_{h}-C_{l}-F_{e}}{F_{e}} \ln \left(\frac{C_{h}-C_{l}-F_{e}}{B-F_{e}}\right) .
\end{aligned}
$$

Corollary 4. The higher the penalties for nonintegrity operation of drug enterprises, the greater the probability that they operate with integrity. The higher the additional costs that drug enterprises need to pay for integrity operation, the

$$
\begin{aligned}
\frac{\partial V_{e 1}}{\partial\left(C_{h}-C_{l}\right)} & =-\frac{1}{F_{e}} \ln \left(\frac{B-F_{e}}{C_{h}-C_{l}-F_{e}}\right)<0, \\
\frac{\partial V_{e 1}}{\partial F_{e}} & =\frac{1}{F_{e}^{2}}\left[C_{h}-C_{l}-B+\left(C_{h}-C_{l}\right) \ln \left(\frac{B-F_{e}}{C_{h}-C_{l}-F_{e}}\right)+\left(\frac{C_{h}-C_{l}-F_{e}}{B-F_{e}}-1\right) F_{e}\right]>0 .
\end{aligned}
$$

smaller the probability that they will choose to operate with integrity.

Proof. According to the probability $V_{e 1}$, the first-order partial derivatives of $\left(C_{h}-C_{l}\right)$ and $F_{e}$ can be calculated:
Corollary 4 shows that punishments imposed by the local government on drug enterprises will restrict the behavior of drug enterprises. With the increase in fines for the nonintegrity operation, drug enterprises will choose the "integrity operation" strategy. When the additional cost of integrity operation of drug enterprises is greater, they will tend to choose the nonintegrity operation for economic benefits.

Corollary 5. The higher the cost for drug enterprises to seek collusion with third-party testing agencies, the lower the probability of the nonintegrity operation of the drug enterprise.

Proof. According to the probability $V_{e 0}$, the first-order partial derivatives of $B$ can be calculated:

$$
\frac{\partial V_{e 0}}{\partial B}=-\frac{1}{F_{e}}\left(1+\frac{C_{h}-C_{l}-F_{e}}{B-F_{e}}\right)<0 .
$$

Corollary 5 shows that when the cost of collusion with third-party testing agencies is greater for drug enterprises, they realize that nonintegrity operation will increase their operating costs. In order to ensure economic benefits, the probability of choosing a "nonintegrity operation" is smaller.

Corollary 6. When $F_{e}>F_{e 0}$, drug enterprises will choose "integrity operation" strategy; when $F_{e}<F_{e 0}$, they will choose "nonintegrity operation" strategy. The threshold is $F_{e 0}=\left(C_{h}-C_{l}-(1-z) B\right) /(z+(1-z) x)$.
Proof. According to Proposition 2, when $H(x)=0, F_{e 0}=$ $\left(C_{h}-C_{l}-(1-z) B\right) /(z+(1-z) x)$ can be calculated. Because $\partial H(x) / \partial F_{e}>0, H(x)$ is an increasing function of $F_{e}$. When $F_{e}>F_{e 0}, H(x)>0,\left.F^{\prime}(y)\right|_{y=1}<0$, and $\left.F(y)\right|_{y=1}=0$ can be calculated. When $F_{e}<F_{e 0}, H(x)<0,\left.F^{\prime}(y)\right|_{y=0}<0$, and $\left.F(y)\right|_{y=0}=0$ can be calculated.

Corollary 6 shows that when drug enterprises do not operate with integrity, they will be punished by the local government. If $F_{e}>F_{e 0}$, it is possible to ensure that the drug enterprises choose an "integrity operation" strategy. Therefore, local government should increase the level of penalties for drug enterprises when they do not operate with integrity, to urge drug enterprises to actively conduct an operation with integrity and protect the health of people.

Corollary 7. When $B>B_{0}$, drug enterprises will choose the "integrity operation" strategy; when $B<B_{0}$, they will choose the "nonintegrity operation" strategy. The threshold is $B_{0}=\left(C_{h}-C_{l}-z F_{e}-(1-z) F_{e}\right) /(1-z)$.

Proof. According to Proposition 2, when $H(x)=0, B_{0}=$ $\left(C_{h}-C_{l}-z F_{e}-(1-z) F_{e}\right) /(1-z)$ can be calculated. Because $\partial H(x) / \partial B>0, H(x)$ is an increasing function of $B$. When $B>B_{0}, H(x)>0,\left.F^{\prime}(y)\right|_{y=1}<0$, and $\left.F(y)\right|_{y=1}=0$ can be calculated. When $B<B_{0}, H(x)<0,\left.F^{\prime}(y)\right|_{y=0}<0$, and $\left.F(y)\right|_{y=0}=0$ can be calculated. 


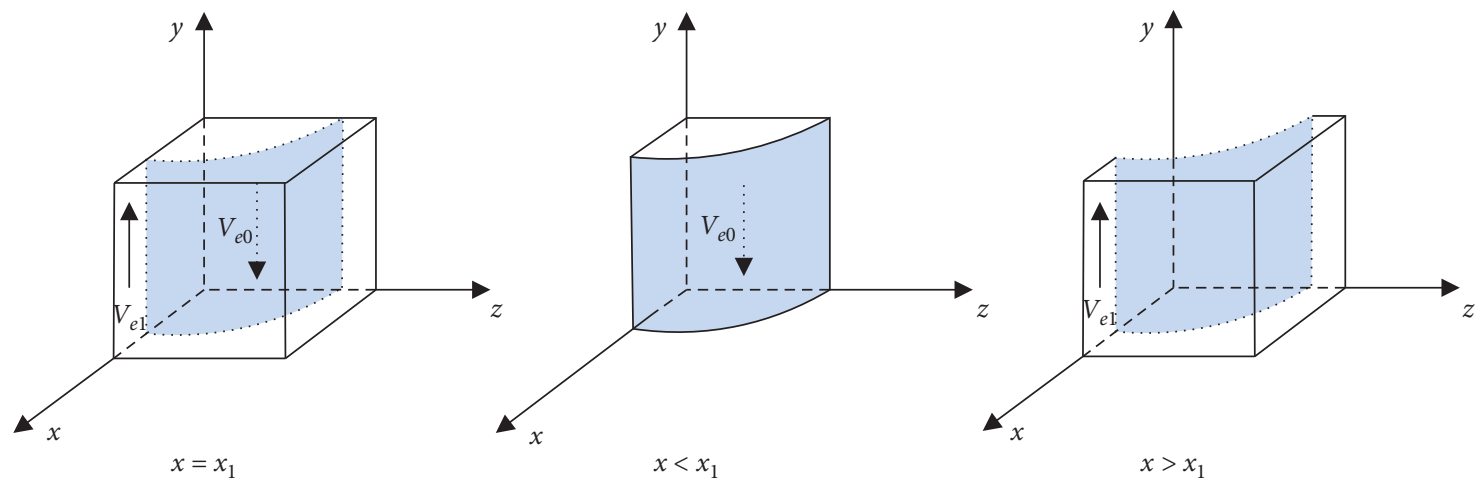

FIgURE 3: Phase diagram of drug enterprises strategic choice.

Corollary 7 shows that when $B>B_{0}$, in order to protect economic interests, drug enterprises will choose the "integrity operation"; when $B<B_{0}$, which means that the cost of collusion by drug enterprises is small, to reduce operating costs and obtain more profits, they will choose the "nonintegrity operation."

\subsection{Third-Party Testing Agencies' Strategic Choice Stability.}

The expected benefit of third-party testing agencies choosing the "noncollusion" strategy is

$$
E_{z}=y\left(V-C_{p}\right)+(1-y)\left(V-C_{p}+M\right)=V-C_{p}+(1-y) M .
$$

The expected benefit of third-party testing agencies choosing the "collusion" strategy is

$$
\begin{aligned}
E_{1-z} & =y\left(V-C_{p}\right)+(1-y) x\left(V+B-F_{p}-C_{p}-C_{t}\right)+(1-y)(1-x)\left(V+B-C_{p}-C_{t}\right) \\
& =y\left(C_{p}-B\right)-(1-y) x F_{p}+V+B-C_{p}-C_{t} .
\end{aligned}
$$

The replicated dynamic equation and the first derivative of the third-party testing agencies' strategic choice are

$$
\begin{aligned}
F(z) & =\frac{\mathrm{d} z}{\mathrm{~d} t}=z\left(E_{z}-\bar{E}\right)=z(1-z)\left(E_{z}-E_{1-z}\right) \\
& =z(1-z)\left[C_{t}-B+(1-y) x F_{p}-y\left(C_{p}-B\right)+(1-y) M\right], \\
F^{\prime}(z) & =(1-2 z)\left[C_{t}-B+(1-y) x F_{p}-y\left(C_{p}-B\right)+(1-y) M\right] .
\end{aligned}
$$

According to the stability theorem of differential equations, if the probability of third-party testing agencies choosing the "noncollusion" strategy is to be in a stable state, the following conditions must be met: $F(z)=0$ and $F^{\prime}(z)<0$.

Proposition 3. When $x>x_{2}$, the third-party testing agencies' stabilization strategy is "noncollusion." When $x<x_{2}$, their stabilization strategy is "collusion." When $x=x_{2}$, we are unable to determine their stabilization strategy. The threshold is $x_{2}=\left(y\left(C_{p}-B\right)-(1-y) M+B-C_{t}\right) /\left((1-y) F_{p}\right)$.

Proof. Make $\quad K(x)=C_{t}-B+(1-y) x F_{p}-y\left(C_{p}-B\right)+$ $(1-y) M$; when $K(x)=0, x_{2}=\left(y\left(C_{p}-B\right)-(1-y) M+\right.$ $\left.B-C_{t}\right) /\left((1-y) F_{p}\right)$ can be calculated. Because $\partial K(x) / \partial x>0, K(x)$ is an increasing function of $x$. When $x>x_{2}, K(x)>0,\left.F^{\prime}(z)\right|_{z=1}<0$, and $\left.F(z)\right|_{z=1}=0$ can be calculated, so $z=1$ is stable. When $x<x_{2}, K(x)<0$, $\left.F^{\prime}(z)\right|_{z=0}<0$, and $\left.F(z)\right|_{z=0}=0$ can be calculated, so $z=0$ is stable. When $x=x_{2}, K(x)=0$, and $F^{\prime}(z)=0$ can be calculated, we are unable to determine a stable strategy.

Proposition 3 shows that when $x$ increases, the stability strategy of third-party testing agencies changes from collusion to noncollusion. Therefore, in order to avoid being punished by the local government and get rewards for participating in the coregulation, third-party testing agencies will choose not to collude with the drug enterprises. Strict supervision by local government will promote third-party testing agencies to fulfill their social responsibilities and consciously provide true testing reports to the coregulation information platform. 
In summary, the response function of $z$ is

$$
z= \begin{cases}0, & \text { if } x<\frac{y\left(C_{p}-B\right)-(1-y) M+B-C_{t}}{(1-y) F_{p}}, \\ {[0,1],} & \text { if } x=\frac{y\left(C_{p}-B\right)-(1-y) M+B-C_{t}}{(1-y) F_{p}}, \\ 1, & \text { if } x>\frac{y\left(C_{p}-B\right)-(1-y) M+B-C_{t}}{(1-y) F_{p}} .\end{cases}
$$

According to Proposition 3, the phase diagram of the third-party testing agencies' strategic choice is shown in Figure 4.

Figure 4 is the phase diagram that shows the evolutionary trend of the third-party testing agencies' strategy obtained by calculating the response function of the probability of the third-party testing agencies choosing the "noncollusion" strategy.

It can be seen from Figure 4 that the volume of $V_{p 1}$ is the probability that the third-party testing agencies choose the "noncollusion" strategy, and the volume of $V_{p 0}$ is the probability that the third-party testing agencies choose the "collusion" strategy. And,

$$
\begin{aligned}
& V_{p 0}=\int_{0}^{1} \int_{0}^{\left(M+C_{t}-B\right) /\left(M+C_{p}-B\right)} \frac{y\left(C_{p}-B\right)-(1-y) M+B-C_{t}}{(1-y) F_{p}} \mathrm{~d} y \mathrm{~d} z=\frac{B-M-C_{t}}{F_{p}}-\frac{C_{p}-C_{t}}{F_{p}} \ln \left[\frac{C_{p}-C_{t}}{F_{p}\left(M+C_{p}-B\right)}\right], \\
& V_{p 1}=1-V_{p 0}=1-\frac{B-M-C_{t}}{F_{p}}+\frac{C_{p}-C_{t}}{F_{p}} \ln \left[\frac{C_{p}-C_{t}}{F_{p}\left(M+C_{p}-B\right)}\right] .
\end{aligned}
$$

Corollary 8. The probability of third-party testing agencies choosing "collusion" is positively related to the cost of drug enterprises seeking to collude and negatively related to the speculative cost of participating in the collusion.

Proof. According to the probability $V_{p 0}$, the first-order partial derivatives of $C_{t}$ and $B$ can be calculated:

$$
\begin{aligned}
& \frac{\partial V_{p 0}}{\partial C_{t}}=-\frac{1}{F_{p}} \ln \left[\frac{F_{p}\left(M+C_{p}-B\right)}{C_{p}-C_{t}}\right]<0, \\
& \frac{\partial V_{p 0}}{\partial B}=\frac{1}{F_{p}}\left(1-\frac{C_{p}-C_{t}}{M+C_{p}-B}\right)>0 .
\end{aligned}
$$

Corollary 8 shows that when the cost of collusion by drug enterprises is higher, third-party testing agencies will tend to choose collusion in order to obtain more benefits; when the speculative cost of collusion by third-party testing agencies is higher, the probability of choosing a "collusion" strategy is lower.

Corollary 9. The probability of third-party testing agencies choosing "noncollusion" is positively related to the fines for collusion and the rewards for noncollusion.

Proof. According to the probability $V_{p 1}$, the first-order partial derivatives of $M$ and $F_{p}$ can be calculated:

$$
\begin{aligned}
& \frac{\partial V_{p 1}}{\partial M}=\frac{1}{F_{p}}\left(1-\frac{C_{p}-C_{t}}{M+C_{p}-B}\right)>0, \\
& \frac{\partial V_{p 1}}{\partial F_{p}}=\frac{B-M-C_{P}}{F_{p}^{2}}+\frac{C_{t}-C_{P}}{F_{p}^{2}} \ln \frac{C_{p}-C_{t}}{F_{p}\left(M+C_{p}-B\right)}>0 .
\end{aligned}
$$

Corollary 9 shows that increasing rewards for third-party testing agencies that do not participate in the collusion can encourage them to fulfill their social responsibilities and consciously provide real drug quality test reports to the coregulation information platform. When the fines for third-party testing agencies participating in collusion increase, they will actively choose "noncollusion."

Corollary 10. When $F_{p}>F_{p 0}$, third-party testing agencies will choose the "noncollusion" strategy; when $F_{p}<F_{p 0}$, they will choose the "collusion" strategy. The threshold is $F_{p 0}=\left(y\left(C_{p}-B\right)+B-C_{t}-(1-y) M\right) /((1-y) x)$.

Proof. According to Proposition 3, when $K(x)=0, F_{p 0}=$ $\left(y\left(C_{p}-B\right)+B-C_{t}-(1-y) M\right) /((1-y) x)$ can be calculated. Because $\partial K(x) / \partial F_{p}>0, K(x)$ is an increasing function of $F_{p}$. When $F_{p}>F_{p 0}, K(x)>0,\left.F^{\prime}(z)\right|_{z=1}<0$, and $\left.F(z)\right|_{z=1}=0$ can be calculated. When $F_{p}<F_{p 0}, K(x)<0$, $\left.F^{\prime}(z)\right|_{z=0}<0$, and $\left.F(z)\right|_{z=0}=0$ can be calculated. 


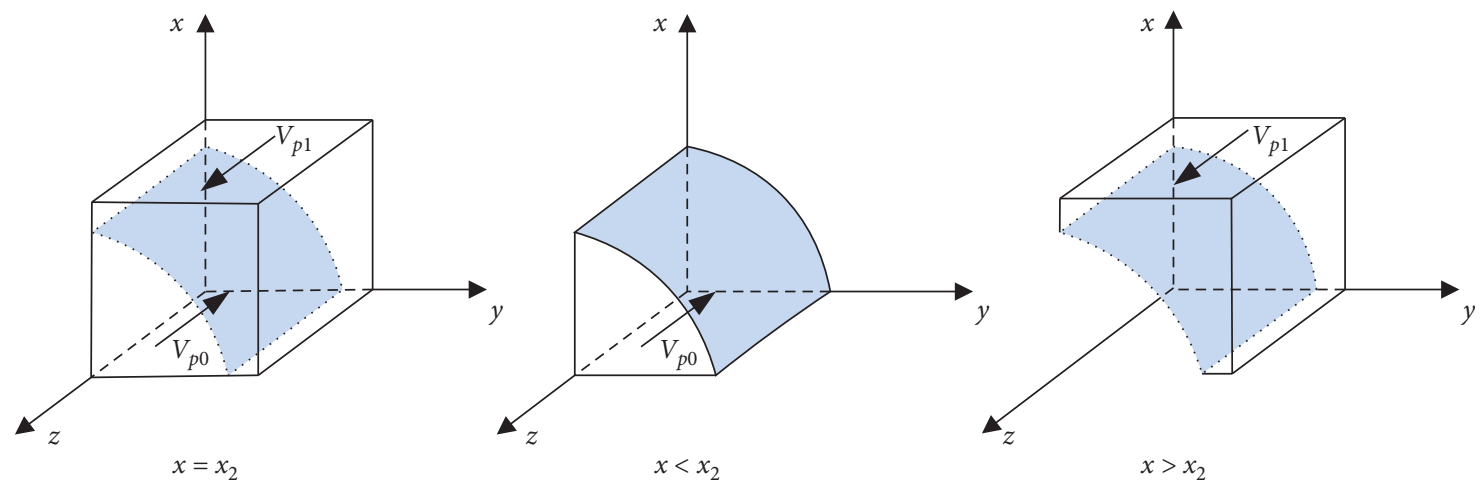

FIGURE 4: Phase diagram of the third-party testing agencies' strategic choice.

Corollary 11. When third-party testing agencies choose to collude, they will be punished by the local government. IfF $p>F_{p 0}$, it is possible to ensure that the third-party testing agencies choose the "noncollusion" strategy. Therefore, when third-party testing agencies participate in collusion, the local government should increase the level of punishment to urge them to provide true test reports.

\section{Stability Analysis of Strategic Combination}

In the replication dynamic system of the tripartite game of local government, drug enterprises, and third-party testing agencies, the stability of each strategic combination can be judged according to Lyapunov's first method. If all the eigenvalues of the Jacobian matrix are negative, the equilibrium point is an evolutionary stable strategy (ESS). If at least one eigenvalue of the Jacobian matrix is positive, the equilibrium point is an unstable point; if the eigenvalues of the Jacobian matrix are all negative except for zero, the equilibrium point is in a critical state and the stability is uncertain. This paper analyzes the stability of the eight pure strategy Nash equilibrium points, according to the replication dynamic equation of the game player, the Jacobian matrix of the replication dynamic system is

$$
J=\left[\begin{array}{lll}
\frac{\partial F(x)}{\partial x} & \frac{\partial F(x)}{\partial y} & \frac{\partial F(x)}{\partial z} \\
\frac{\partial F(y)}{\partial x} & \frac{\partial F(y)}{\partial y} & \frac{\partial F(y)}{\partial z} \\
\frac{\partial F(z)}{\partial x} & \frac{\partial F(z)}{\partial y} & \frac{\partial F(z)}{\partial z}
\end{array}\right] .
$$

5.1. Stability of Strategic Combination in Noncollusion. When the stability strategy of the third-party testing agencies is "noncollusion," that is, when condition $C_{t}+F_{p}>B$ is satisfied, the asymptotic stability analysis of the equilibrium point of the replicated dynamic system is shown in Table 3.

It can be seen from Table 3 that if the third-party testing agencies are not colluding, when $C_{h}-C_{l}<F_{e}$, the equilibrium point $(0,1,1)$ of the replicated dynamic system is ESS.
When $F_{g}<G_{h}-G_{l}$ and $F_{e}<C_{h}-C_{l}$, the equilibrium point $(0,0,1)$ of the replicated dynamic system is ESS. When $F_{g}>G_{h}-G_{l}$ and $F_{e}<C_{h}-C_{l}$, the equilibrium point $(1,0,1)$ of the replicated dynamic system is ESS.

Therefore, in order to encourage drug enterprises to operate with integrity, the local government should increase the penalty for the nonintegrity drug enterprises, thereby increasing the price that drug enterprises have to pay for the nonintegrity operation. In order to encourage local government to actively use the real information provided by third-party testing agencies to the coregulation information platform to strictly supervise drug enterprises, the central government should increase penalties for local government with loose supervision, thereby encouraging local government to take the initiative to strictly supervise drug enterprises, give full play to the role of third-party testing agencies, and maintain good market order.

5.2. Stability of Strategic Combination in Collusion. When the stability strategy of the third-party testing agencies is "collusion," that is, when condition $M<B-C_{t}-F_{p}$ is satisfied, the asymptotic stability analysis of the equilibrium point of the replicated dynamic system is shown in Table 4.

It can be seen from Table 4 that if third-party testing agencies choose to collude, when $C_{h}-C_{l}>B$ and $G_{h}-G_{l}>F_{e}+F_{p}$, the equilibrium point $(0,0,0)$ of the replicated dynamic system is ESS. When $C_{h}-C_{l}>B+F_{e}$ and $G_{h}-G_{l}<F_{e}+F_{p}$, the equilibrium point $(1,0,0)$ of the replicated dynamic system is ESS. When $C_{h}-C_{l}<B$, the equilibrium point $(0,1,0)$ of the replication dynamic system is ESS.

Therefore, in order to encourage third-party testing agencies not to participate in collusion and provide real drug quality test reports to the coregulation information platform, punishment for participation in collusion should be increased, and they should be urged to consciously fulfill their social responsibilities. In order to encourage drug enterprises to operate with integrity and consciously produce high-quality drugs, the government should increase the cost of seeking collusion and urge them to actively operate with integrity to protect the lives and health of the people. 
TABLE 3: Asymptotic stability of the equilibrium point in noncollusion.

\begin{tabular}{|c|c|c|c|}
\hline Equilibrium point & Eigenvalues $\lambda_{1}, \lambda_{2}, \lambda_{3}$ & Sign & Stability \\
\hline$(0,1,1)$ & $G_{l}-G_{h}, C_{h}-C_{l}-F_{e}, C_{p}-C_{t}$ & $(-, \times, \times)$ & When condition (1) is satisfied, it is ESS \\
\hline$(1,1,1)$ & $G_{h}-G_{l}, C_{h}-C_{l}-F_{e}, C_{p}-C_{t}$ & $(+, \times, \times)$ & Unstable \\
\hline$(0,0,1)$ & $F_{g}+G_{l}-G_{h}, F_{e}+C_{l}-C_{h}, B-C_{t}-M$ & $(\times, \times, \times)$ & When condition (2) is satisfied, it is ESS \\
\hline$(1,0,1)$ & $G_{h}-G_{l}-F_{g}, F_{e}+C_{l}-C_{h}, B-C_{t}-F_{p}-M$ & $(\times, \times, \times)$ & When condition (3) is satisfied, it is ESS \\
\hline
\end{tabular}

Note. $\times$ indicates that the sign is uncertain. If the conditions (1), (2), and (3) are met, they are, respectively, stable points. Condition (1): $C_{h}-C_{l}<F_{e}, C_{p}<C_{t}$; condition (2): $F_{g}<G_{h}-G_{l}, F_{e}<C_{h}-C_{l}, B-C_{t}<M$; condition (3): $F_{g}>G_{h}-G_{l}, F_{e}<C_{h}-C_{l}, B-C_{t}-F_{p}<M$.

TABLe 4: Asymptotic stability of the equilibrium point in collusion.

\begin{tabular}{lccc}
\hline Equilibrium point & Eigenvalues $\lambda_{1}, \lambda_{2}, \lambda_{3}$ & Sign & Stability \\
\hline$(0,0,0)$ & $G_{l}-G_{h}+F_{e}+F_{p}, C_{l}-C_{h}+B, C_{t}-B+M$ & $(\times, \times, \times)$ & When condition (4) is satisfied, it is ESS \\
$(1,0,0)$ & $G_{h}-G_{l}-F_{e}-F_{p}, C_{l}-C_{h}+B+F_{e}, C_{t}-B+M+F_{p}$ & $(\times, \times, \times)$ & When condition (5) is satisfied, it is ESS \\
$(0,1,0)$ & $G_{l}-G_{h}, C_{h}-C_{l}-B, C_{t}-C_{p}$ & $(-, \times, \times)$ & When condition (6) is satisfied, it is ESS \\
$(1,1,0)$ & $G_{h}-G_{l}, C_{h}-C_{l}-F_{e}-B, C_{t}-C_{p}$ & $(+, \times, \times)$ & Unstable \\
\hline
\end{tabular}

Note. $\times$ indicates that the sign is uncertain. If the conditions (4),(5), and (6) are met, they are, respectively, stable points. Condition (4): $G_{h}-G_{l}>F_{e}+F_{p}$, $C_{h}-C_{l}>B, B>C_{t}+M$; condition (5): $G_{h}-G_{l}<F_{e}+F_{p}, C_{h}-C_{l}>B+F_{e}, B>C_{t}+M+F_{p}$; condition (6): $C_{h}-C_{l}<B, C_{t}<C_{p}$.

\section{Simulation Analysis}

In order to more intuitively reflect the impact of the changes of various decision variables on the evolution process and evolution results of the multiparty game, MATLAB 2020b is used for numerical simulation to verify the validity of the evolutionary stability analysis.

Based on the actual conditions and the research of other scholars, this paper makes assumptions about the numerical values. The additional cost of the local government's strict supervision is $G_{h}-G_{l}=10$. The additional cost of drug enterprises for integrity operation is $C_{h}-C_{l}=7.0$ and the income from the operation of them is $R=15$. The cost of testing by third-party testing agencies is $C_{p}=2.0$ and the testing income of them is $V=8.0$. The local government is punished by the central government at $F_{g}=3.0$ for loose supervision; the penalty for the nonintegrity operation of drug enterprises is $F_{e}=4.0$; and punishment for collusion by third-party testing agencies is $F_{p}=3.0$. The cost of drug enterprises seeking collusion is $B=4.0$. The speculative cost of the third-party testing agencies is $C_{t}=1.0$ and their noncolluding reward from the local government is $M=2.0$. The social benefit of the local government is $H=3.0$.

6.1. Impact of Reward. Set the reward for the third-party testing agencies not to participate in the collusion as $M=\{0.0,5.6,18.3\}$. The evolution process and results of the players' strategy of the tripartite game are shown in Figure 5.

Figure 5 is the simulation diagram that shows the influence of the rewards obtained by third-party testing agencies not participating in the collusion on the strategic choices of local government, drug enterprises, and thirdparty testing agencies.

Figure 5 shows that when there is no reward, local government will choose loose supervision, drug enterprises choose nonintegrity operation, and third-party testing agencies participate in collusion. When the number of rewards for noncolluding increases, third-party testing agencies will be more proactive in choosing noncolluding strategies and timely and proactively provide real drug quality testing reports to the coregulation information platform. However, at this time, local government and drug enterprises still choose loose supervision and nonintegrity operation. It can be seen that the increase in rewards will promote third-party testing agencies to fulfill their social responsibilities, but it is not conducive to local government to perform its own duties. It is necessary to reasonably set the number of rewards and stimulate the enthusiasm of all entities to participate in coregulation supervision of drug enterprises' integrity operation.

6.2. Impact of Additional Cost. Suppose the additional cost $G_{h}-G_{l}=\{5.0,7.0,9.0\}$ that the local government needs to pay when choosing a strict supervision strategy, and the additional cost $C_{h}-C_{l}=\{3.0,5.0,7.0\}$ that drug enterprises need to pay for choosing an integrity operation strategy. The tripartite game evolutionary process and results of local government, drug enterprises, and third-party testing agencies are shown in Figure 6.

Figure 6 is the simulation diagram that shows the influence of the additional cost that the local government needs to pay on the strategic choices of local government, drug enterprises, and third-party testing agencies.

It can be seen from Figure 6 that when the additional cost of the integrity operation of drug enterprises is low, there is an evolutionary stable equilibrium point $(0,1,1)$ in the replication dynamic system. At this time, the drug enterprises operate with integrity, third-party testing agencies do not participate in collusion, and the local government does not need to conduct strict supervision. As the additional costs paid by local government and drug enterprises increase, the replication dynamic system is in an unstable state; when the additional costs paid by drug enterprises and local government further increase, the evolutionary stable equilibrium point of the replication dynamic system is $(0,0,0)$. At this time, the local government loosely supervises, drug 


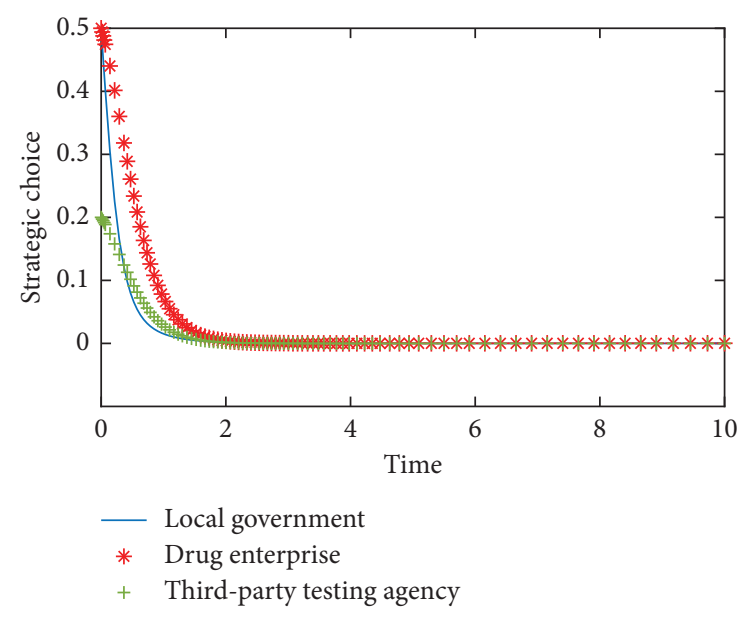

(a)

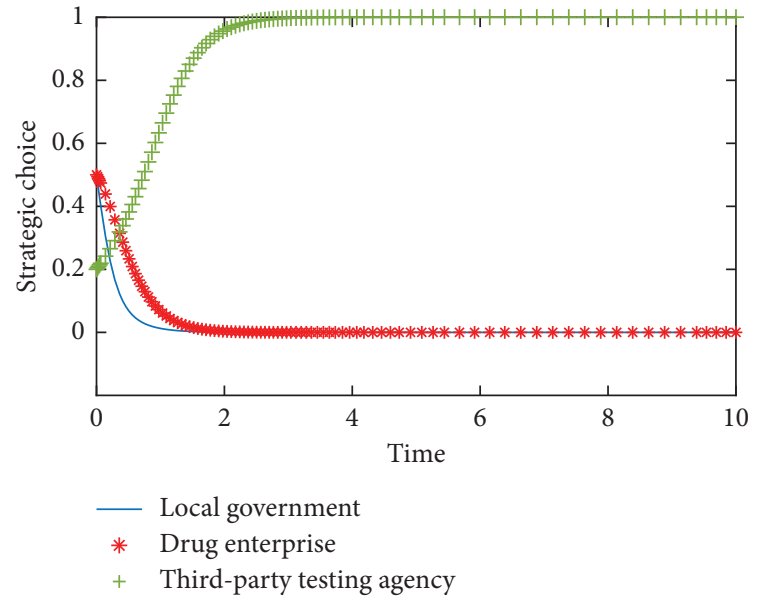

(b)

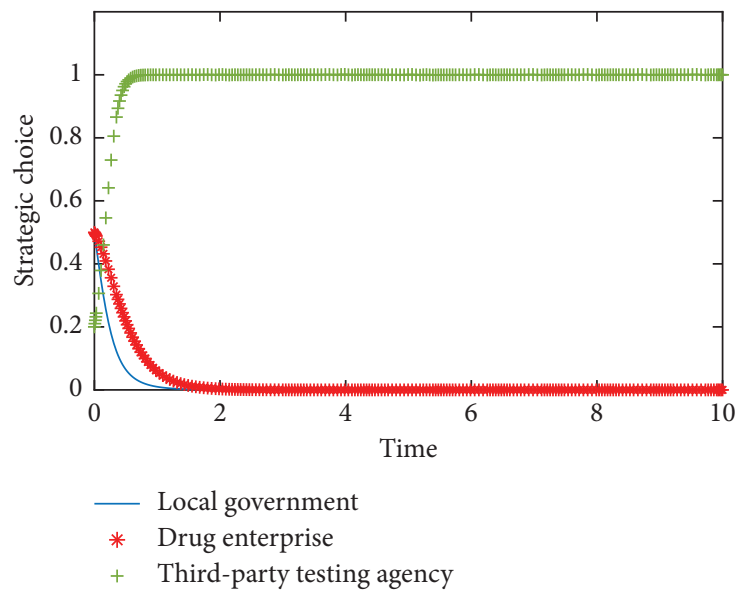

(c)

Figure 5: Impact of rewards on the evolution of each player's strategy.

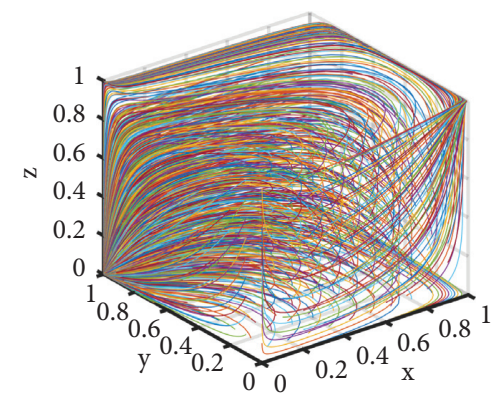

(a)

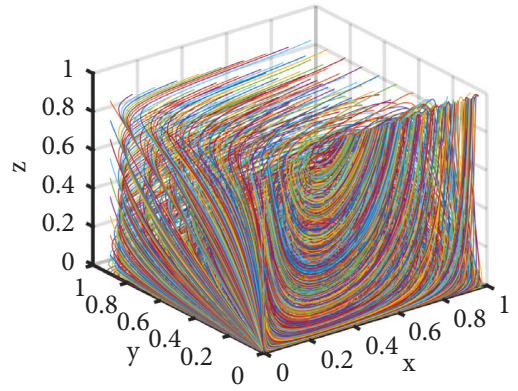

(b)

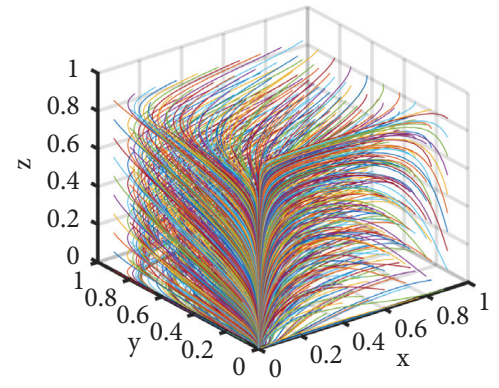

(c)

FIGURE 6: Impact of additional costs on the evolution of each player's strategy.

enterprises do not operate with integrity, and third-party testing agencies participate in collusion.

6.3. Impact of Penalty. The local government is punished by the central government as $F_{g}=\{0.0,7.0,20\}$ when they choose the loose supervision strategy. When drug enterprises choose the nonintegrity operation strategy, they are punished by the local government as $F_{e}=\{0.0,6.0,10\}$; when third-party testing agencies choose collusion strategies, they are punished by the local government as $F_{p}=\{0.0,6.0,8.0\}$. The tripartite game evolutionary process and results of local government, drug enterprises, third-party testing agencies are shown in Figure 7.

Figure 7 is the simulation diagram that shows the influence of the penalties on the strategic choices of local 


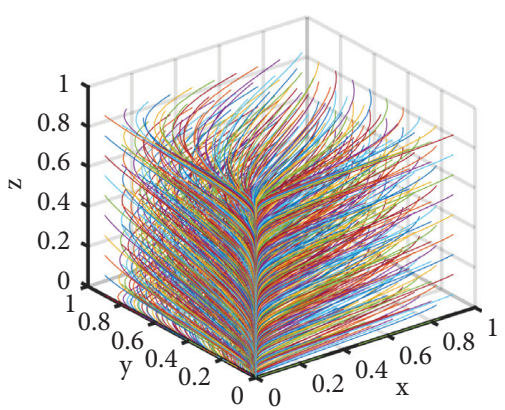

(a)

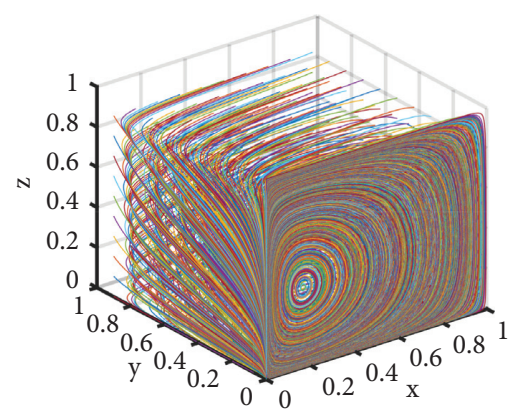

(b)

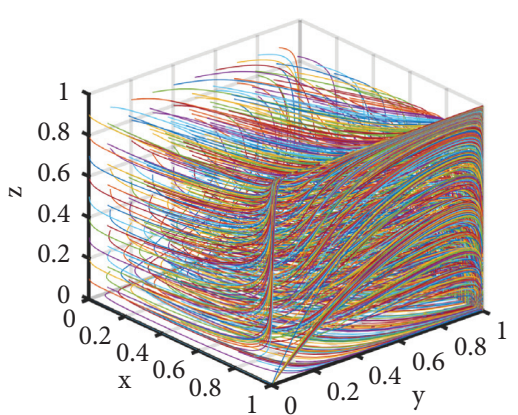

(c)

Figure 7: Impact of penalties on the evolution of each player's strategy.

government, drug enterprises, and third-party testing agencies.

It can be seen from Figure 7 that when there is no penalty, the equilibrium point evolves to $(0,0,0)$; at this time, the loose supervision by local government, nonintegrity operation of drug enterprises, and the participation of third-party testing agencies in collusion will seriously affect market order and the health of people. With the increase of punishment, the dynamic replication system is in an unstable state, and the strategic combination of game players is not stable. When the penalties for loose supervision by the local government further increase, the penalties for the nonintegrity operation of drug enterprises further increase, and the penalties for third-party testing agencies to participate in collusion further increase; the evolutionary stable equilibrium point of the strategic choices of local government, drug enterprises, and third-party testing agencies is $(1,1,1)$. Therefore, penalties have a binding effect on the behavior of local government, drug enterprises, and third-party testing agencies. When establishing a monitoring mechanism for the integrity operation of drug enterprises, the government should pay attention to the design of the reward and punishment mechanism, and effective punishment is of great significance to supervising the integrity operation of drug enterprises.

\section{Discussion}

This paper considers the government reward and punishment mechanism, studies the coregulation supervision of drug enterprises' integrity operation, and builds an evolutionary game model which involves the participation of local government, drug enterprises, and third-party testing agencies. The stable equilibrium point of each game player's strategic choice is solved, the stability of the strategic combination of the replication dynamic system is analyzed, and MATLAB 2020b is used for simulation analysis. Besides, this paper analyzes the influence of the change of each decision variable on the strategy evolution and puts forward the following suggestions.

First of all, in the coregulation supervision of the integrity operation of drug enterprises, when local government is aware of drug enterprises actively fulfilling its social responsibilities, in order to reduce the cost of supervision and protect social interests, the local government will choose loose supervision.

Secondly, the local government and third-party testing agencies can supervise drug enterprises, encourage thirdparty testing agencies to provide real drug quality testing reports to the coregulation information platform in a timely manner, and promote the coregulation supervision structure of integrity operation of drug enterprises which is of great significance to social development.

Besides, improve the sense of responsibility of local government and third-party testing agencies. Encourage third-party testing agencies to actively participate in coregulation and feedback drug enterprises' information to the coregulation information platform timely. Therefore, it can improve supervision efficiency and promote the formation of a social coregulation work pattern.

Eventually, penalties and rewards can effectively increase the enthusiasm of local government, drug enterprises, and third-party testing agencies to participate in the supervision of drug enterprises' integrity operation, so that local government will strictly supervise, the drug enterprises will operate with integrity, and third-party testing agencies will not participate in collusion.

\section{Conclusions}

The nonintegrity operation of drug enterprises will seriously affect the health of patients and will have a great negative impact on market order, economic development, and social stability. Therefore, to actively play the role of the government reward and punishment mechanism, the central government should strengthen the supervision of the work of local government, implement an accountability system, and impose severe penalties (such as admonishment talks and administrative dismissal) on local government with loose supervision. It should strengthen the supervision of the behavior of drug enterprises, increase penalties for them, and urge them to operate with integrity. It should also increase rewards for third-party testing agencies that actively provide real test reports to the coregulation information platform to promote the formation of a good coregulation supervision order and penalize third-party testing agencies 
that participate in the collusion to urge them to consciously perform social responsibility and play an active supervisory role.

Considering the impact of the reward and punishment mechanism on the strategic choices of local government, drug enterprises, and third-party testing agencies, this paper constructs a three-party evolutionary game model. However, the constructed game model is fully informative and singlestage under bounded rationality, and the game sequence is not considered. Therefore, considering the condition of incomplete information, construct a multistage, repetitive, and dynamic game model with multiagent participation is the next research direction.

\section{Data Availability}

All the data are available within the manuscript.

\section{Conflicts of Interest}

The authors declare that no conflicts of interest.

\section{Acknowledgments}

This work was supported by the National Social Science Foundation of China under Grant nos. 20BGL272 and 21ZDA024.

\section{References}

[1] H. Long, H. Liu, X. Li, and L. Chen, “An evolutionary game theory study for construction and demolition waste recycling considering green development performance under the Chinese government's reward-penalty mechanism," International Journal of Environmental Research and Public Health, vol. 17, no. 17, p. 6303, 2020.

[2] D. Friedman, "On economic applications of evolutionary game theory," Journal of Evolutionary Economics, vol. 8, no. 1, pp. 15-43, 1998.

[3] D. Challet and Y. C. Zhang, "Emergence of cooperation and organization in an evolutionary game," Physica A: Statistical Mechanics and its Applications, vol. 246, no. 3, pp. 407-418, 1997.

[4] S. Babu and U. Mohan, "An integrated approach to evaluating sustainability in supply chains using evolutionary game theory," Computers \& Operations Research, vol. 89, pp. 269283, 2018.

[5] G. M. Hodgson and K. Huang, "Evolutionary game theory and evolutionary economics: are they different species?" Journal of Evolutionary Economics, vol. 22, no. 2, pp. 345-366, 2012.

[6] X. Li, R. Huang, J. Dai, J. Li, and Q. Shen, "Research on the evolutionary game of construction and demolition waste (CDW) recycling units' green behavior, considering remanufacturing capability," International Journal of Environmental Research and Public Health, vol. 18, no. 17, p. 9268, 2021.

[7] V. Ahuja, C. Alvarez, J. R. Birge, and C. Syverson, "Enhancing regulatory decision making for postmarket drug safety," Management Science, 2021.

[8] D. Ronan, W. Stuart, and S. Salek, "Factors influencing quality decision-making: regulatory and pharmaceutical industry perspectives," Pharmacoepidemiology and Drug Safety, vol. 24, no. 3, pp. 319-328, 2015.

[9] A. Raghav, Z. A. Khan, V. K. Upadhayay et al., "Mesenchymal stem cell-derived exosomes exhibit promising potential for treating SARS-CoV-2-infected patients," Cells, vol. 10, no. 3, pp. 587-608, 2021.

[10] Y. A. Karbassi, M. M. Farhan, P. F. Wanke, O. Figueiredo, and I. Mushtaq, "Critical success factors for competitive advantage in Iranian pharmaceutical companies: a comprehensive MCDM approach," Mathematical Problems in Engineering, 2021.

[11] L. Wenli, W. Zhaoman, W. Zhong, and G. Bing, "Sustainable recycle network of heterogeneous pharmaceuticals with governmental subsidies and service-levels of third-party logistics by bi-level programming approach," Journal of Cleaner Production, vol. 249, no. 5, pp. 1-17, 2020.

[12] M. Filip, "Pharmacovigilance; drug safety monitoring," Journal of Pharmacological Reports, vol. 5, no. 2, pp. 1-2, 2021.

[13] B. Magdalena, M. Neil, and L. Lawrence, "The qualitative value of facilitated regulatory pathways in europe, USA, and Japan: benefits, barriers to utilization, and suggested solutions," Pharmaceutical Medicine, 2021.

[14] Z. Manman, Z. Juliang, T. C. E. Cheng., H. Guowei et al., "The effect of unannounced inspection on prevention of drug fraud," Journal of Systems Science and Systems Engineering, vol. 28, no. 1, pp. 63-90, 2018.

[15] W. Mengxue, "Performance evaluation of listed pharmaceutical companies based on EVA," Academic Journal of Engineering and Technology Science, 2020.

[16] T. Dănescu and M. Popa, "Public health and corporate social responsibility: exploratory study on pharmaceutical companies in an emerging market," Globalization and Health, vol. 16, no. 1, pp. 117-125, 2020.

[17] L. Jian, W. He, U. Carolina, and H. Hao, "PP162 digital medication health service platforms of pharmaceutical companies as novel sources of real-world data for health technology assessment," International Journal of Technology Assessment in Health Care, vol. 36, no. 1, p. 18, 2020.

[18] W. Ricciardi, B. P. Pita, A. Bourek, W. Brouwer, T. Kelsey, and L. Lehtonen, "How to govern the digital transformation of health services," The European Journal of Public Health, vol. 29, no. 3, pp. 7-12, 2019.

[19] L. Changjoon and H. ByoungChun, "Interactional justice, informational quality, and sustainable supply chain management: a comparison of domestic and multinational pharmaceutical companies," Sustainability, vol. 13, no. 2, pp. 998-1014, 2021.

[20] Z. Ranran and M. Weimin, "Assessing the role of reward and punishment mechanism in house price regulation in China: a game-theoretic approach," Journal of Urban Planning and Development, 2020.

[21] B. Magdalena, M. Neil, P. Connelly, and S. R. Walker, "Quality decision-making practices in pharmaceutical companies and regulatory authorities: current and proposed approaches to its documentation," Therapeutic innovation \& regulatory science, vol. 54, no. 6, pp. 1404-1415, 2020.

[22] L. Parker, A. Bennett, B. Mintzes et al., “"There are ways drug companies will get into DTC decisions": how Australian drug and therapeutics committees address pharmaceutical industry influence," British Journal of Clinical Pharmacology, vol. 87, no. 5, pp. 2341-2353, 2020.

[23] W. Zeyuan and C. Yang, "Research on the influence of political connection and social influence on the social responsibility of listed pharmaceutical companies," World Scientific Research Journal, vol. 6, no. 8, pp. 121-130, 2020. 
[24] C. Hong, F. Qun, and C. Jing, "Rent-seeking mechanism for safety supervision in the Chinese coal industry based on a tripartite game model," Energy Policy, vol. 72, pp. 140-145, 2014.

[25] N. Jain, S. Hasija, and S. Netessine, "Supply chains and antitrust governance," Management Science, 2021.

[26] H. Dorothée and H. Kyle, "Flexibility and reputation in repeated prisoner's dilemma games," Management Science, 2020 . 